DE ALMEIDA LEITE, Rodrigo; BORGES GAMA NETO, Ricardo. O recurso por incumprimento perante o tribunal europeu de direitos humanos: um reforço jurídico ao mecanismo político de supervisão de sentenças. Revista Eletrônica Direito e Política, Programa de Pós-Graduação Stricto Sensu em Ciência Jurídica da UNIVALI, Itajaí, v.14, n.1, $1^{0}$ quadrimestre de 2019. Disponível em: www.univali.br/direitoepolitica - ISSN 1980-7791

\title{
O RECURSO POR INCUMPRIMENTO PERANTE O TRIBUNAL EUROPEU DE DIREITOS HUMANOS: UM REFORÇO JURÍDICO AO MECANISMO POLÍTICO DE SUPERVISÃO DE SENTENÇAS
}

\author{
THE INFRINGEMENT PROCEEDINGS IN THE EUROPEAN COURT OF HUMAN \\ RIGHTS: A LEGAL REINFORCEMENT TO THE POLITICAL MECHANISM OF \\ SUPERVISION OF JUDGMENTS
}

\author{
Rodrigo de Almeida Leite ${ }^{1}$ \\ Ricardo Borges Gama Neto
}

\section{RESUMO}

O presente trabalho pretende discutir os impactos do Recurso por Incumprimento no âmbito do mecanismo de supervisão do cumprimento de sentenças do Tribunal Europeu dos Direitos Humanos (TEDH). Para este objetivo, parte de uma metodologia bibliográfica-documental, analisando o desenho institucional da supervisão antes e depois da entrada em vigor do Protocolo n. 14 (norma esta que instituiu o recurso). Como o processo de supervisão de sentenças do Sistema Europeu de Direitos Humanos era eminentemente político, realizado pelo Comitê de Ministros, o recurso se mostra como um reforço jurídico para persuadir os Estados. No entanto, a análise demonstrou que embora este recurso ainda não tenha sido utilizado, a doutrina ressalta uma série de críticas ao novo procedimento, tendo em vista questões práticas e as graves consequências políticas que ele pode causar, como por exemplo, a expulsão do Sistema de um país que insiste em não executar uma sentença do TEDH.

Palavras-chave: Supervisão; Cumprimento; Sentenças; Recurso; Tribunal Europeu dos Direitos Humanos.

\begin{abstract}
The present work intends to discuss the impacts of the Infringement Proceedings within the mechanism of supervision of compliance with judgments of the European Court of Human Rights (ECtHR). For this purpose, begin of a bibliographical-documentary methodology, analyzing the institutional design of supervision before and after the entry into force of Protocol n. 14 (the rule establishing the appeal). As the process of supervising sentences of the European
\end{abstract}

\footnotetext{
${ }^{1}$ Doutor em Ciência Política pela UFPE. Mestre em Direito Comunitário pela Universidade de Lisboa. Graduado em Direito pela Universidade Católica de Pernambuco. Professor Adjunto de Direito da Universidade Federal Rural do Semi-Árido (UFERSA), onde também é Professor e Coordenador do Curso de Especialização em Direito Constitucional e Tributário.

2 Doutor e Mestre em Ciência Política pela UFPE. Professor do Programa de Pós Graduação em Ciência Política da UFPE, com trabalhos na área de Política Comparada com uso de métodos quantitativos. Foi diretor da Associação Brasileira de Ciência Política (2012 - 2016).
} 
DE ALMEIDA LEITE, Rodrigo; BORGES GAMA NETO, Ricardo. O recurso por incumprimento perante o tribunal europeu de direitos humanos: um reforço jurídico ao mecanismo político de supervisão de sentenças. Revista Eletrônica Direito e Política, Programa de Pós-Graduação Stricto Sensu em Ciência Jurídica da UNIVALI, Itajaí, v.14, n.1, $1^{0}$ quadrimestre de 2019. Disponível em: www.univali.br/direitoepolitica - ISSN 1980-7791

System of Human Rights was eminently political, carried out by the Committee of Ministers, the appeal appears as a legal reinforcement to persuade States. However, the analysis has shown that although this resource has not yet been used, the doctrine highlights a number of criticisms of the new procedure, in view of practical issues and the serious political consequences it can cause, such as expulsion from the System of a country that insists on not executing a judgment of the ECtHR.

Keywords: Supervision; Execution; Judgments; Appeal; European Court of Human Rights.

\section{INTRODUÇÃO}

O Sistema Europeu de Direitos Humanos, criado em 1949, através do Conselho da Europa, tem exercido um papel relevante no tocante à proteção dos direitos humanos na Europa e demais países membros. Este fato revela-se não somente pela qualidade e quantidade de sentenças que são proferidas pelo Tribunal Europeu de Direitos Humanos (TEDH), mas também pelo nível de cumprimento das sentenças desta Corte. Neste sentido, os estudos de Grewal e Voeten ${ }^{3}$, Voeten ${ }^{4}$, e Anagnostou e Mungiu-Pippidi ${ }^{5}$, demonstraram um bom nível de execução das decisões do TEDH.

Embora não se possa atribuir o sucesso do cumprimento de sentenças unicamente pelo prestígio e nível de organização do Sistema Europeu, deve-se ressaltar que existe no Conselho da Europa um mecanismo de supervisão do cumprimento de sentenças que exerce grande influência ${ }^{6}$ nos países, por meio de procedimentos

\footnotetext{
3 GREWAL, Sharanbir; VOETEN, Erik. The Politics of Implementing European Court of Human Rights Judgements, 2012, Paper disponível em SSRN: <https://ssrn.com/abstract=1988258>. Acesso em: 9 nov. 2018.

${ }^{4}$ VOETEN, Erik. Does a Professional Judiciary Induce More Compliance?: Evidence from the European Court of Human Rights. Paper prepared for presentation at the ISA Convention, San Diego April, 2012, p. 20 1-39. Disponível <https://www.jus.uio.no/pluricourts/english/projects/multirights/docs/voeten-legaljustifications.pdf >. Acesso em: 10 nov. 2018.

${ }^{5}$ ANAGNOSTOU, Dia; MUNGIU-PIPPIDI, Alina. Domestic Implementation of Human Rights Judgments in Europe: Legal Infrastructure and Government Effectiveness Matter. The European Journal of International Law, vol. 25, n. 1, 2014, p. 205-227.

${ }^{6}$ Cfr. GARCÉS, Andrée Viana. Sistemas Europeo y Americano de Protección de Derechos Humanos. Coincidencias, Fraccionamientos Temporales y Mutuas Influencias. In: SÁNCHEZ, Miguel Revenga; GARCÉS, Andrée Viana (eds.): Tendencias Jurisprudenciales de La Corte Interamericana y el Tribunal Europeo de Derechos Humanos. Valencia: Tirant lo Blanch, 2008, p. 17-70; e ÇALI,
} 
DE ALMEIDA LEITE, Rodrigo; BORGES GAMA NETO, Ricardo. O recurso por incumprimento perante o tribunal europeu de direitos humanos: um reforço jurídico ao mecanismo político de supervisão de sentenças. Revista Eletrônica Direito e Política, Programa de Pós-Graduação Stricto Sensu em Ciência Jurídica da UNIVALI, Itajaí, v.14, n.1, $1^{0}$ quadrimestre de 2019. Disponível em: www.univali.br/direitoepolitica - ISSN 1980-7791

regulamentados e espaços de diálogo e pressão, além da previsão de sanções em casos extremos de descumprimento de decisões. Todos esses instrumentos são comandados pelo Comitê de Ministros da organização, órgão eminentemente político que foi criado desde a origem do Sistema e aprimorado recentemente.

Sobre a importância deste processo de supervisão, Hillebrecht ${ }^{7}$ aponta que apesar do cumprimento das sentenças das Cortes de Direitos Humanos estar relacionado diretamente com as questões político-institucionais nacionais, o desenho institucional destes tribunais e seus órgãos de supervisão de cumprimento de sentnças têm grande importância na execução das sentenças.

Apenas à título de comparação, o Sistema Interamericano de Direitos Humanos possui um baixo nível de cumprimento integral das sentenças da Corte Interamericana (Corte IDH). Os estudos empíricos sobre o tema realizados por Cavallaro e Brewer ${ }^{8}$, Bash et al. ${ }^{9}$, Hawkins e Jacoby ${ }^{10}$, Huneeus ${ }^{11}$, GonzálezSalzberg ${ }^{12}$ e Zaverucha e Leite ${ }^{13}$ coincidiram em mostrar que os Estados condenados

Basaki; $\mathrm{KOCH}$, Anne. Foxes Guarding the Foxes? The Peer Review of Human Rights Judgments by the Committee of Ministers of the Council of Europe. Human Righs Law Review, vol. 14, 2014 , p. 301-325.

7 HILLEBRECHT, Courtney. Domestic Politics and International Human Rights Tribunals. The Problem of Compliance. New York: Cambridge University Press, 2014.

8 CAVALLARO, James L; BREWER, Stephanie. Reevaluating Regional Human Rights Litigation in the Twenty-First Century: The Case of the Inter-American Court. The American Journal of International Law, vol. 102, 2008, p. 768-827.

9 BASCH, Fernando; FILIPPINI, Leonard; LAYA, Ana; NINO, Mariano; et al. The Effectiveness of the Inter-American System of Human Rights Protection: A Quantitative Approach to its Functioning and Compliance with its Decisions. SUR - International Journal on Human Rights, vol. 7, n. 12, 2010, p. 9-36.

10 HAWKINS, Darren; JACOBY, Wade. Partial compliance: a comparison of the European and interAmerican courts of human rights. Journal of International Law and International Relations, vol. 6, n. 1, 2010, p. 35-85.

11 HUNEEUS, Alexandra. Courts Resisting Courts: Lessons from the Inter-American Court's Struggle to Enforce Human Rights. Cornell International Law Journal, vol. 44, 2011, p. 493-533.

12 GONZÁLEZ-SALZBERG, Damián A. The Effectiveness Of The Inter-American Human Rights System: A Study Of The American States' Compliance With The Judgments Of The Inter-American Court Of Human Rights. International Law: Revista Colombiana de Derecho Internanacional, n. 15, 2010, p. 115-142.

13 ZAVERUCHA, Jorge.; LEITE, Rodrigo de Almeida. A impunidade de agentes estatais nos casos julgados pela Corte Interamericana. Revista Brasileira de Segurança Pública, vol. 10, n. 1, 2016, p. 88-107. 
DE ALMEIDA LEITE, Rodrigo; BORGES GAMA NETO, Ricardo. O recurso por incumprimento perante o tribunal europeu de direitos humanos: um reforço jurídico ao mecanismo político de supervisão de sentenças. Revista Eletrônica Direito e Política, Programa de Pós-Graduação Stricto Sensu em Ciência Jurídica da UNIVALI, Itajaí, v.14, n.1, $1^{0}$ quadrimestre de 2019. Disponível em: www.univali.br/direitoepolitica - ISSN 1980-7791

cumprem as medidas de reparações mais fáceis de maneira mais frequente e rápida, como as indenizações, as medidas simbólicas e as envolvendo apenas a ação do Poder Executivo, enquanto que medidas que demandam a ação de dois ou mais poderes costumam ser cumpridas parcialmente.

Como já ressaltado, este baixo nível de cumprimento, ainda que não seja gerado por fatores relativos ao Sistema Interamericano em si, poderia ser diminuído por meio de uma atuação da Organização dos Estados Americanos (OEA), como organização internacional responsável pelo Sistema. No entanto, a impressão exposta pela doutrina ${ }^{14}$ é que a organização não tem se importado se os países membros do Sistema Interamericano não cumprem as sentenças da Corte IDH.

No caso do Sistema Interamericano, por mais que a própria Corte Interamericana realize a supervisão de suas sentenças por meio de audiências e recebimentos de escritos das partes, carece, na prática, de um suporte dos órgãos políticos da OEA (que seriam o Conselho Permanente e a Assembleia Geral), para poder pressionar ou incentivar os países a cumprirem as decisões.

Em ambos os sistemas (interamericano e europeu), existem estruturas semelhantes. Os tribunais respectivos recebem queixas de indivíduos particulares e Estados, e existem trâmites processuais com características similares que

\footnotetext{
${ }^{14}$ Neste sentido, vid. entre outros, BRICEÑO-DONN, Marcela. El papel de los actores del Sistema Interamericano en el Proceso de Fortalecimiento. Revista IIDH, n. 30-31, 2001, p. 237-243; ODRÍA, Alberto Borea. Propuesta de modificación a la legislación del sistema interamericano de protección de los derechos humanos. In: Corte Interamericana de Derechos Humanos (org.). EI Sistema Interamericano de Protección de los Derechos Humanos en el Umbral del Siglo XXI, 2a. ed., Corte Interamericana de Derechos Humanos, San José, 2003, p. 533-546; KRSTICEVIC, V.: Reflexiones sobre la ejecución de sentencias de las decisiones del sistema interamericano de protección de derechos humanos. In: KRSTICEVIC, V.; TOJO, L. (coord.): Implementación de las decisiones del Sistema Interamericano de Derechos Humanos: Jurisprudencia, normativa y experiencias nacionales. Buenos Aires: Center for Justice and International Law - CEJIL, 2007, p. 15-112; RODRÍGUEZ-PINZÓN, Diego; MARTIN, Claudia. The Inter-American human rights system: selected examples of its supervisory work. In: JOSEPH, Sarah.; MCBETH, Adam. (eds.). Research Handbook on International Human Rights Law. Northampton: Edward Elgar Publishing Limited, 2010, p. 353-387; SCHNEIDER, Jan. Implementation of Judgments: Should Supervision Be Unlinked From The General Assembly Of The Organization Of American States? Revista Interamericana y Europea de Derechos Humanos - InterAmerican and European Human Rights Journal ,v. 5, n.1, 2012, p. 197-215; e LEITE, Rodrigo. Análise Dos Processos E Atores Políticos Na Supervisão De Sentenças Da Corte Interamericana De Direitos Humanos. In: Simone P. Viscarra; Michele G. Massuchin; Sandra Avi dos Santos; Lucas R. Mesquita; Lorena Granja Hernández; Helga N. Almeida. (Org.). América Latina em foco: Novas perspectivas de análise sobre a região. 1ed. Porto Alegre: Terra da Ideia, 2017, p. 99-119.
} 
DE ALMEIDA LEITE, Rodrigo; BORGES GAMA NETO, Ricardo. O recurso por incumprimento perante o tribunal europeu de direitos humanos: um reforço jurídico ao mecanismo político de supervisão de sentenças. Revista Eletrônica Direito e Política, Programa de Pós-Graduação Stricto Sensu em Ciência Jurídica da UNIVALI, Itajaí, v.14, n.1, $1^{0}$ quadrimestre de 2019. Disponível em: www.univali.br/direitoepolitica - ISSN 1980-7791

culmina com uma decisão judicial. No entanto, uma das questões distintas entre os dois sistemas é justamente como se supervisiona o cumprimento das decisões das Cortes respectivas.

No caso do Sistema Europeu, até o ano de 2010 o mecanismo de supervisão do cumprimento de sentenças do TEDH era eminentemente político, exercido pelo Comitê de Ministros. Com a entrada em vigor do Protocolo n. 14, em 2010, foi criado o recurso por incumprimento. Este recurso é cabível quando o Comitê, após considerar esgotadas as tentativas político-diplomáticas de fazer com que um Estado cumpra uma sentença do Tribunal, decide enviar o caso de volta à Corte Europeia de Direitos Humanos para que sejam tomadas as medidas que considerar adequadas.

Ainda que esta via processual seja um reforço a mais ao procedimento político de supervisão, ela ainda não foi utilizada até o momento, tendo em vista, entre outras questões, o forte impacto político que reveste esta medida. Como exemplo, o acionamento do recurso pode resultar na expulsão de um Estado membro do Conselho da Europa. Por esta e outros fatores, a doutrina europeia, embora tenha elogiado a criação desta via recursal, também teceu críticas contundentes ${ }^{15}$.

Neste sentido, pelo caráter relevante e ainda recente do procedimento, serão realizadas considerações sobre o recurso. Para tanto, será analisada brevemente a estrutura do Sistema Europeu de Direitos Humanos, para em seguida abordarse como funciona o mecanismo de supervisão de sentenças do TEDH, exaltandose o papel do Comitê de Ministros e os procedimentos existentes para o acompanhamento da execução das decisões. Em continuação, será apresentada a processualística do recurso por incumprimento, além das consequências e críticas positivas e negativas.

\footnotetext{
${ }^{15}$ As críticas serão apresentadas no capítulo 3.
} 
DE ALMEIDA LEITE, Rodrigo; BORGES GAMA NETO, Ricardo. O recurso por incumprimento perante o tribunal europeu de direitos humanos: um reforço jurídico ao mecanismo político de supervisão de sentenças. Revista Eletrônica Direito e Política, Programa de Pós-Graduação Stricto Sensu em Ciência Jurídica da UNIVALI, Itajaí, v.14, n.1, $1^{0}$ quadrimestre de 2019. Disponível em: www.univali.br/direitoepolitica - ISSN 1980-7791

\section{O SISTEMA EUROPEU DE PROTEÇÃO DOS DIREITOS HUMANOS}

A partir do fim da Segunda Guerra Mundial, teve início um movimento para criação dos sistemas regionais de direitos humanos. O primeiro deles foi o Sistema Europeu de Proteção dos Direitos Humanos.

A criação do Conselho da Europa teve lugar em 5 de maio de 1949, formada inicialmente por dez países (França, Reino Unido, os três países do Benelux, Irlanda, Itália, Dinamarca, Noruega e Suécia). O objetivo era estabelecer uma maior proteção dos direitos fundamentais na Europa e ressaltar os valores democráticos. Em consequência, em 4 de novembro de 1950, os países assinaram a Convenção Europeia dos Direitos Humanos (CEDH), que entrou em vigor em 3 de setembro de 1953. Esse tratado era a norma básica que continha o rol de direitos a serem garantidos e a forma como se daria o funcionamento dos órgãos do sistema: a Secretaria Geral; o Comitê de Ministros, que é o órgão político decisório e que tem entre suas missões a de supervisionar o cumprimento das sentenças; a Assembleia Parlamentar; a Comissão Europeia de Direitos Humanos (já extinta), que funcionava como um órgão quase judicial, recebendo as queixas e direcionando-as ao Tribunal; e o Tribunal Europeu dos Direitos Humanos.

A instituição desse tribunal permitiu que, após esgotadas as vias judiciais internas dos países membros, os particulares interpusessem uma queixa direcionada à Comissão, que avaliaria se houve ou não violação da $\mathrm{CEDH}$, encaminhando o processo para o TEDH em caso positivo. Após o proferimento da sentença condenatória do Estado membro, é dado aos países um prazo para cumprir as obrigações determinadas, enquanto o Comitê de Ministros inicia um procedimento de supervisão, que envolve pressão política e cooperação (incentivos) para que os Estados executem as medidas ordenadas.

Com o passar dos anos, a CEDH sofreu diversas alterações, sendo a eliminação da Comissão, por meio do Protocolo no 11 , que entrou em vigor em $1^{0}$ de novembro de 1998, uma das mais importantes, pois permitiu que as pessoas levassem suas queixas diretamente ao TEDH. 
DE ALMEIDA LEITE, Rodrigo; BORGES GAMA NETO, Ricardo. O recurso por incumprimento perante o tribunal europeu de direitos humanos: um reforço jurídico ao mecanismo político de supervisão de sentenças. Revista Eletrônica Direito e Política, Programa de Pós-Graduação Stricto Sensu em Ciência Jurídica da UNIVALI, Itajaí, v.14, n.1, $1^{0}$ quadrimestre de 2019. Disponível em: www.univali.br/direitoepolitica - ISSN 1980-7791

Frise-se que especialistas consideram o TEDH um dos mais efetivos órgãos internacionais de monitoramento e julgamento de violações dos direitos humanos $^{16}$. E esse sucesso se deu em parte porque o projeto europeu relacionou o tema dos direitos humanos com a integração dos países, envolvendo a política e a economia ${ }^{17}$, ainda que o Conselho da Europa trate especificadamente da proteção dos direitos humanos.

A inovação do Sistema Europeu, em criar um tribunal para julgar violações de direitos humanos adveio da consciência de que o tratado que estipulava o rol de direitos do sistema requeria a autoridade de uma decisão judicial. A experiência do passado mostrou que a publicação de opiniões por meras "comissões" poderia ser ignorada ${ }^{18}$.

No entanto, ainda que haja uma decisão judicial direcionada aos Estados que se comprometeram em cumpri-las ao firmarem a $\mathrm{CEDH}$, sanções pelo não cumprimento das sentenças não podem ser impostas. Mesmo assim, a pressão política e outras implicações que são geradas pelo não cumprimento são importantes meios para persuadir os Estados a obedecerem às decisões do TEDH ${ }^{19}$.

Nesse sentido, ainda que muita atenção sobre o Sistema Europeu tenha sido dada ao TEDH ou à CEDH, é importante destacar que existe um conjunto de mecanismos operando no Conselho da Europa aplicando diversas metodologias, como o acompanhamento do cumprimento das sentenças pelo Comitê de Ministros, Assembleia Parlamentar e Secretaria Geral, visitas nos países, pressão diplomática e política, assistência técnica pela Diretoria Geral de Direitos Humanos,

\footnotetext{
16 MANTOUVALOU, Virginia; VOYATZIS, Panayotis. The Council of Europe and the protection of human rights. In: JOSEPH, Sarah; MCBETH, Adam. Research handbook on international human rights Law. Reino Unido: Edward Elgar, 2010, p. 329; e CHRISTOFFERSEN, Jonas; MADSEN, Mikael Rask. Introduction. In: CHRISTOFFERSEN, Jonas; MADSEN, Mikael Rask (eds.). The European Court of Human Rights between Law and Politics. New York: Oxford University Press, 2011, p. 2.

17 CHRISTOFFERSEN, Jonas; MADSEN, Mikael Rask. Introduction, p. 1.

${ }^{18}$ BATES, Ed. The Evolution of the European Convention on Human Rights: From Its Inception to the Creation of a Permanent Court of Human Rights. New York: Oxford University Press, 2011, p. 26.

19 MANTOUVALOU, Virginia; VOYATZIS, Panayotis. The Council of Europe and the protection of human rights, p. 331.
} 
DE ALMEIDA LEITE, Rodrigo; BORGES GAMA NETO, Ricardo. O recurso por incumprimento perante o tribunal europeu de direitos humanos: um reforço jurídico ao mecanismo político de supervisão de sentenças. Revista Eletrônica Direito e Política, Programa de Pós-Graduação Stricto Sensu em Ciência Jurídica da UNIVALI, Itajaí, v.14, n.1, $1^{0}$ quadrimestre de 2019. Disponível em: www.univali.br/direitoepolitica - ISSN 1980-7791

aconselhamento de especialistas, entre outras. Essa multiplicidade de dispositivos é indicativa do fato de que uma abordagem multifacetada (combinação de mecanismos legais, políticos e diplomáticos) é necessária para resolver os problemas mais complexos dos direitos humanos experimentada pelo descumprimento das sentenças ${ }^{20}$.

Essa atuação conjunta se firma principalmente com dois órgãos principais: o Comitê de Ministros e a Assembleia Parlamentária (além da Secretaria Geral). O primeiro tem como missão específica velar pelo cumprimento das sentenças. 0 Conselho da Europa preferiu dotar o Comitê de Ministros, um órgão político, da missão de acompanhar a execução das sentenças, deixando o TEDH mais livre para apenas trabalhar com a parte judicial. Em complemento, a Assembleia Parlamentar possui, entre outras funções, a de acompanhar a execução das sentenças, ainda que indiretamente. Seu papel nessa área se dá principalmente no questionamento por escrito e oral aos membros do Comitê de Ministros sobre o porquê de uma sentença não estar sendo cumprida, além de poder convocar os representantes diplomáticos dos países condenados para dar explicações sobre os $\operatorname{casos}^{21}$.

\section{A SUPERVISÃO DO CUMPRIMENTO DE SENTENÇAS}

O Comitê de Ministros, órgão político do Conselho da Europa, recebeu a missão de supervisionar a execução das sentenças definitivas do TEDH, nos termos do art. 46.2 da $\mathrm{CEDH}^{22}$. Esse sistema de controle do cumprimento de decisões se exerce

${ }^{20} \mathrm{LEACH}$, Philip. Taking a Case to the European Court of Human Rights. 3a. ed. New York: Oxford University Press, 2011, p. 407-408.

${ }^{21}$ ABDELGAWAD, Elisabeth Lambert. The Court as part of the Council of Europe: the Parliamentary Assembly and the Committee of Ministers. In: FOLLESDAL, Andreas; PETERS, Birgit; ULFSTEIN, Geir (eds). Constituting Europe. The European Court of Human Rights in a National, European and Global Context. Cambridge, Cambridge University Press, 2013, p. 263-284.

22 Art. 46, CEDH: "Força vinculativa e execução das sentenças. 1. As Altas Partes Contratantes obrigam-se a respeitar as sentenças definitivas do Tribunal nos litígios em que forem partes. 2. A sentença definitiva do Tribunal será transmitida ao Comité de Ministros, o qual velará pela sua execução. [...]". In: CONSELHO DA EUROPA. Convenção Europeia dos Direitos do Homem. 
DE ALMEIDA LEITE, Rodrigo; BORGES GAMA NETO, Ricardo. O recurso por incumprimento perante o tribunal europeu de direitos humanos: um reforço jurídico ao mecanismo político de supervisão de sentenças. Revista Eletrônica Direito e Política, Programa de Pós-Graduação Stricto Sensu em Ciência Jurídica da UNIVALI, Itajaí, v.14, n.1, $1^{0}$ quadrimestre de 2019. Disponível em: www.univali.br/direitoepolitica - ISSN 1980-7791

por meio do convite do Estado condenado para que entregue um plano de ação e relatórios de ação sobre a execução das medidas de reparação ordenadas nas sentenças ${ }^{23}$.

No entanto, o papel do Comitê de Ministros é muito maior. Ele é o órgão decisório do Conselho da Europa. O seu papel e funções são descritos no Capítulo IV do Estatuto da Organização ${ }^{24}$. O Comitê de Ministros se reúne em três níveis: (a) ministerial, com a participação dos Ministros das Relações Exteriores de cada Estado membro, com reuniões uma vez ao ano; (b) de Deputados, em que, de acordo com art. 14 do Estatuto do Conselho da Europa, cada Ministro da Relações Exteriores nomeia um Deputado para agir em seu nome, com reuniões três vezes por semana; e (c) de Deputados de Direitos Humanos (também indicados), cujas reuniões são dedicadas exclusivamente à supervisão da execução de sentenças do TEDH e ocorrem pelo menos quatro vezes por ano, tendo uma duração de dois ou três dias cada. Os Deputados são assessorados pelo Gabinete dos Deputados, Relatores e grupos de trabalho e grupos ad hoc ${ }^{25}$.

Essa obrigação específica de velar pela execução das sentenças faz com que o Comitê de Ministros assuma uma natureza coletiva, pois ele é composto por representantes de todos os Estados membros do Conselho da Europa ${ }^{26}$. A supervisão do Comitê de Ministros ultrapassa a simples verificação do pagamento

Roma, 4 nov. 1950. Disponível em: <https://www.echr. coe.int/Documents/Convention_POR.pdf>. Acesso em: 9 nov. 2018.

23 Tanto os planos de ação como os relatórios de cada caso, podem ser encontrados no site do Comitê de Ministros, no menu de Supervisão de Sentenças, entrando-se na seção de documentos (procurese "action plans e action reports from Respondent States"), disponível em: <https://www.coe.int/en/web/cm/execution-judgments>. Acesso em 01 maio 2019.

24 Estatuto do Conselho da Europa, aprovado em 5 maio 1949. Disponível em: <http://www.coe.int/en/web/conventions/full-list/-/conventions/rms/0900001680306052>. Acesso em 18 nov. 2018.

25 Os grupos de trabalho são os seguintes: 1 - Educação, cultura, esporte, juventude e meio ambiente; 2 -Democracia; 3 - Relações exteriores; 4 - Direitos humanos; 5 - Cooperação jurídica; 6 - Programa, orçamento e administração; 7 - Questões sociais e de saúde. Para maiores informações, vide o site dos grupos, disponível em: <http://www.coe.int/en/web/cm/subsidiarygroups>.

26 PIRES, Maria José Morais. Execução dos Acórdãos do Tribunal Europeo dos Direitos do Homem O Protocolo n. 14 à Convenção Europeia dos Direitos do Homem. In: MIRANDA, Jorge (coord). Homenagem ao Prof. Doctor André Gonçalves Pereira. Lisboa: Ed. Coimbra, 2006, p. 829. 
DE ALMEIDA LEITE, Rodrigo; BORGES GAMA NETO, Ricardo. O recurso por incumprimento perante o tribunal europeu de direitos humanos: um reforço jurídico ao mecanismo político de supervisão de sentenças. Revista Eletrônica Direito e Política, Programa de Pós-Graduação Stricto Sensu em Ciência Jurídica da UNIVALI, Itajaí, v.14, n.1, $1^{0}$ quadrimestre de 2019. Disponível em: www.univali.br/direitoepolitica - ISSN 1980-7791

de uma indenização e entra na questão do mérito da sentença. Nesse sentido, três são os principais pontos que o Comitê de Ministros supervisiona: (a) o pagamento de uma indenização às vítimas (e/ou familiares); (b) outras medidas individuais ${ }^{27}$, em que o simples pagamento indenizatório não repara o dano; e (c) medidas gerais $^{28}$, que talvez sejam as mais importantes, pois possuem a missão de prevenir novas violações do mesmo tipo.

Para o exercício de sua missão, o Comitê de Ministros criou um regulamento de aplicação do art. 46.2 da CEDH, que estabelece as linhas gerais para o trabalho de supervisão ${ }^{29}$. Assim, conta com a boa vontade dos Estados na entrega de informações relativas às execuções das sentenças em que foram condenados, que são muitas vezes prestadas por escrito e verbalmente nas reuniões do Comitê. Esse regulamento, além de conduzir a forma das reuniões do Comitê, permite também aos cidadãos e entes terceiros enviar petições sobre o cumprimento das medidas de reparação das sentenças.

Em linhas gerais, o processo de supervisão começa com a entrada da sentença definitiva do TEDH na agenda do Comitê, o que na prática não tarda mais do que seis semanas ${ }^{30}$. O Comitê, então, verifica a concretização das medidas de execução das sentenças por meio de pedidos de informações, que quase sempre são respondidos pelos Estados. Caso as informações não sejam suficientes, o processo permanece na agenda do Comitê de Ministros.

\footnotetext{
27 Dentro do conceito de outras medidas individuais, pode-se citar: a reabertura de um processo judicial, a ordem para absolvição, o cancelamento de um registro criminal, a liberdade de um preso, entre outros.

28 Como exemplo de medidas gerais, pode-se citar: criação de uma nova legislação no país condenado, publicação e disseminação do conteúdo das sentenças, instruções dirigidas às autoridades relevantes nacionais, realização de cursos ou treinamento de funcionários públicos.
}

29 CONSELHO DA EUROPA. Rules of the Committee of Ministers for the supervision of the execution of judgments and of the terms of friendly settlements. Adopted by the Committee of Ministers on 10 May 2006 at the 964th meeting of the Ministers' Deputies and amended on 18 January 2017 at the 1275th meeting of the Ministers' Deputies. Estrasburgo, França, 10 maio 2006. Disponível em: <https://rm.coe.int/16806eebfo>. Acesso em: 9 nov. 2018.

30 SUNDBERG, Fredrik G. E. Control of Execution of Decisions Under the ECHR - Some Remarks on the Committee of Ministers' Control of the Proper Implementation of Decisions Finding Violations of The Convention. In: ALFREDSSON, Gudmundur; GRIMHEDEN, Jonas; RAMCHARAN, Bertram G. et al (eds.). International Human Rights. Monitoring Mechanisms. Essay in Honour of Jakob Th. Moller. Haya: Martinus Nijhoff Publishers, 2001, p. 568. 
DE ALMEIDA LEITE, Rodrigo; BORGES GAMA NETO, Ricardo. O recurso por incumprimento perante o tribunal europeu de direitos humanos: um reforço jurídico ao mecanismo político de supervisão de sentenças. Revista Eletrônica Direito e Política, Programa de Pós-Graduação Stricto Sensu em Ciência Jurídica da UNIVALI, Itajaí, v.14, n.1, $1^{0}$ quadrimestre de 2019. Disponível em: www.univali.br/direitoepolitica - ISSN 1980-7791

O Comitê, depois de ter constatado o efetivo cumprimento das medidas de reparação ordenadas na sentença, aprova uma Resolução formal de conclusão em cada caso.

Caso a sentença não seja executa integralmente, o Comitê de Ministros pode emitir uma Resolução Provisória, na qual se toma nota sobre o andamento da execução da sentença e se propõem as medidas necessárias ao cumprimento das sentenças. Somente depois de constatado o cumprimento total é que é proferida a Resolução final que encerra o caso.

O papel do Comitê de Ministros na supervisão das sentenças é essencial. No entanto, carece de um meio jurídico-coercitivo par forçar um Estado membro a executar as sentenças do TEDH. Nesse sentido, pode-se afirmar que a pressão que exerce o Comitê de Ministros em um Estado que descumpre uma sentença é de natureza político-diplomática, e se funda basicamente em dois instrumentos: a adoção de Resoluções Provisórias e a ameaça do uso do art. $8^{\circ}$ do Estatuto do Conselho da Europa.

No caso das Resoluções Provisórias, de acordo com o art. 16 do Regulamento do Comitê de Ministros sobre a execução de sentenças, este órgão pode tomar a iniciativa de adotar uma Resolução quando considera que a informação proporcionada por um governo de um Estado não demonstra uma execução satisfatória de uma sentença e que ele deve ser incentivado a tal ação. A Resolução tanto pode dar-se quando nenhuma medida para a execução da decisão foi adotada por um Estado ou quando o Comitê observa um determinado progresso na execução, e o incentiva a adotar futuras medidas para evitar os mesmos danos.

Por sua vez, a utilização do art. $8^{\circ}$ do Estatuto do Conselho da Europa ${ }^{31}$ é uma atitude a ser tomada somente em casos extremos. De acordo com esse dispositivo, um Estado membro pode ser suspenso da organização em caso de violação grave

\footnotetext{
31 Art. $8^{\circ}$ do Estatuto do Conselho da Europa: "Any member of the Council of Europe which has seriously violated Article 3 may be suspended from its rights of representation and requested by the Committee of Ministers to withdraw under Article 7. If such member does not comply with this request, the Committee may decide that it has ceased to be a member of the Council as from such date as the Committee may determine".
} 
DE ALMEIDA LEITE, Rodrigo; BORGES GAMA NETO, Ricardo. O recurso por incumprimento perante o tribunal europeu de direitos humanos: um reforço jurídico ao mecanismo político de supervisão de sentenças. Revista Eletrônica Direito e Política, Programa de Pós-Graduação Stricto Sensu em Ciência Jurídica da UNIVALI, Itajaí, v.14, n.1, $1^{\circ}$ quadrimestre de 2019. Disponível em: www.univali.br/direitoepolitica - ISSN 1980-7791

do art. $3^{\circ}$ do Estatuto, que faz referência aos objetivos do Conselho da Europa. Assim, caso se negue a cumprir uma sentença do TEDH, pode ter suspenso o direito de representação na organização. Caso insista no descumprimento, o Comitê de Ministros poderá expulsar o Estado.

Neste sentido, afirma-se que a execução das sentenças do TEDH está nas mãos da boa vontade dos Estados, ainda que haja uma pressão política, além de uma eventual ameaça de sanção de suspensão e expulsão do Conselho da Europa pelo não cumprimento de uma sentença. Frise-se que a medida mais grave de suspensão e expulsão da organização nunca foi tomada pelo Comitê.

Assim, a forma de pressão mais utilizada se dá pela publicização das resoluções do Comitê de Ministros sobre as sentenças em processo de supervisão, que permite às organizações não governamentais (ONGs), instituições nacionais de direitos humanos e o público em geral tomar conhecimento das práticas negativas dos Estados. O resultado é que com a publicização dos fatos, a opinião pública exerça pressão nos órgãos responsáveis nacionais.

Como não existe um meio coercitivo mais eficaz, com sanções mais duras para os Estados que não cumprem as sentenças do TEDH, resta ao Comitê de Ministros utilizar o esforço clássico da diplomacia internacional para tentar gerenciar a supervisão das sentenças e ir pressionando e incentivando os países com os meios que possui. Como será visto adiante, com a introdução de um novo procedimento de supervisão no Comitê de Ministros a partir de 2011, fomentou-se um perfil cooperativo de supervisão que os países membros quiseram implantar no Conselho da Europa, em detrimento de um processo sancionatório ou inquisitório.

\subsection{Procedimentos de Supervisão no Comitê de Ministros}

Após o TEDH proferir uma sentença condenatória, esta é transmitida ao Comitê de Ministros para a supervisão do seu cumprimento. Essa transmissão se dá em um prazo médio de seis semanas. 
DE ALMEIDA LEITE, Rodrigo; BORGES GAMA NETO, Ricardo. O recurso por incumprimento perante o tribunal europeu de direitos humanos: um reforço jurídico ao mecanismo político de supervisão de sentenças. Revista Eletrônica Direito e Política, Programa de Pós-Graduação Stricto Sensu em Ciência Jurídica da UNIVALI, Itajaí, v.14, n.1, $1^{0}$ quadrimestre de 2019. Disponível em: www.univali.br/direitoepolitica - ISSN 1980-7791

Antes da reforma dos procedimentos de supervisão no Comitê, este órgão recebia os planos de ação dos Estados sobre cada sentença e realizava a supervisão com base em um procedimento único, que incidia em discussão dos casos nas reuniões periódicas dos Deputados responsáveis, ao passo que o Comitê de Ministros seguia proferindo decisões, resoluções e recomendações sobre a execução das medidas reparatórias. Quando os Estados reportavam que executavam todas as medidas ordenadas, o Comitê de Ministros analisava as ações e emitia uma resolução de encerramento do caso. Em geral, os ministros das Relações Exteriores de cada país participavam das reuniões com os Deputados do Comitê de Ministros.

A partir da Alta Conferência Intergovernamental de Interlaken, em 201032, os Estados se comprometeram a criar um novo procedimento de modo a agilizar o processo de supervisão e dar maior transparência aos documentos envolvidos. Assim, criaram dois procedimentos de supervisão: o procedimento padrão (standard procedure) e o procedimento intensificado (enhaced procedure).

O procedimento intensificado é dedicado ao julgamento de casos que possuem: (a) medidas individuais urgentes; (b) casos pilotos ${ }^{33}$; (c) sentenças que demandam um problema estrutural ou complexo de maior importância; e (d) casos interestatais ${ }^{34}$. Em geral são processos que demandam um maior trabalho político de gerenciamento, e por isso, ficam sob responsabilidade do Comitê de Ministros. Os demais casos são classificados dentro do procedimento padrão.

Quando a sentença condenatória final ingressa no Comitê de Ministros, ela entra na pauta das reuniões para que seja definido sobre qual procedimento ela irá ser supervisionada. A decisão não é permanente, pois, com o passar do tempo, o

\footnotetext{
32 Vide Declaração de Interlaken em: <https://rm.coe.int/1680593073>. Acesso em 18 nov. 2018.

33 Casos pilotos são aqueles nos quais o TEDH detecta que há um problema estrutural no ordenamento jurídico do país que faz com que a CEDH seja constantemente violada. Assim, o Tribunal suspende todos os casos que se repetem durante a supervisão da execução da sentença de um caso piloto identificado. Desse modo, as medidas de caráter geral que o Comitê de Ministros em geral solicita ao país são que sejam criados recursos internos que permitam resolver todos os casos semelhantes, e posteriormente o TEDH envia os processos suspensos de volta à esfera nacional, para que sejam solucionados de acordo com as modificações efetuadas.

${ }^{34}$ Casos interestatais são processos em que um Estado parte apresenta uma queixa no TEDH contra outro Estado.
} 
DE ALMEIDA LEITE, Rodrigo; BORGES GAMA NETO, Ricardo. O recurso por incumprimento perante o tribunal europeu de direitos humanos: um reforço jurídico ao mecanismo político de supervisão de sentenças. Revista Eletrônica Direito e Política, Programa de Pós-Graduação Stricto Sensu em Ciência Jurídica da UNIVALI, Itajaí, v.14, n.1, $1^{0}$ quadrimestre de 2019. Disponível em: www.univali.br/direitoepolitica - ISSN 1980-7791

Comitê de Ministros pode decidir passar um caso do procedimento intensificado para o padrão, e vice-versa.

Desde a escolha do procedimento até a resolução final que encerra o caso, o Comitê de Ministros conta com o apoio fundamental do Departamento de Execução de Sentenças do TEDH. Este órgão é vinculado ao Comitê de Ministros e possui como função aconselhar e auxiliar o Comitê em sua missão de supervisão da execução das sentenças do TEDH ${ }^{35}$.

A doutrina já reconheceu que o Departamento de Execução de Sentenças é o principal motor do processo de execução ${ }^{36}$, pois assegura um acompanhamento detalhado e contínuo do progresso da execução de todas as sentenças, independentemente do procedimento de supervisão (padrão ou intensificado).

O Departamento de Execução ainda estabelece relações com os Estados membros, mantendo um diálogo bilateral com as autoridades nacionais para promover o processo de execução, em particular por meio de avaliações antecipadas de planos de ação/relatórios de ação, assim como realiza reuniões regulares, além de fornecer consultoria e apoio técnico, promovendo reuniões com todos os atores nacionais envolvidos na execução das sentenças, e prepara atividades de treinamento de pessoal ${ }^{37}$.

Após a sentença passar pelo crivo do Comitê de Ministros, que com o apoio do Departamento de Execução indica qual o tipo de procedimento de supervisão para cada caso, o Estado condenado apresenta um relatório de ação, documento este que serve para demonstrar ao Comitê de Ministros de que modo será executada a sentença. Em geral esse documento é apresentado num prazo de seis meses após

\footnotetext{
35 Vid. Mandate of the Department for the Execution of Judgments of the European Court of Human Rights, disponível em: <https://rm.coe.int/16805a997c>. Acesso em: 18 nov. 2018.

36 Cfr. ÇALI, Basaki; KOCH, Anne. Foxes Guarding the Foxes? The Peer Review of Human Rights Judgments by the Committee of Ministers of the Council of Europe; ALCEGA, Sergio Salinas. El nuevo procedimiento de control de la ejecucion de las sentencias del Tribunal Europeo de Derechos Humanos tras el proceso de Interlaken. La evolución técnica de un mecanismo político. Revista General de Derecho Europeo, n. 36, 2015, p. 1-25; e ABDELGAWAD, Elisabeth Lambert. Dialogue and the implementation of the European Court of Human Rights' Judgments. Netherlands Quarterly of Human Rights, vol. 34/4, 2016, p. 340-363.

37 Vid. Mandate of the Department for the Execution of Judgments of the European Court of Human Rights, disponível em: <https://rm.coe.int/16805a997c>. Acesso em: 18 nov. 2018.
} 
DE ALMEIDA LEITE, Rodrigo; BORGES GAMA NETO, Ricardo. O recurso por incumprimento perante o tribunal europeu de direitos humanos: um reforço jurídico ao mecanismo político de supervisão de sentenças. Revista Eletrônica Direito e Política, Programa de Pós-Graduação Stricto Sensu em Ciência Jurídica da UNIVALI, Itajaí, v.14, n.1, $1^{\circ}$ quadrimestre de 2019. Disponível em: www.univali.br/direitoepolitica - ISSN 1980-7791

a sentença ingressar no Comitê. Após a análise e concordância do Departamento de Execução, o Estado passa a implementar as medidas de reparação, e periodicamente apresenta um relatório de ação, mostrando as ações que foram executadas. Em caso de execução integral da sentença, o Comitê de Ministros arquiva o processo por meio de uma resolução final. Caso o Estado não tenha implementado todas as medidas necessárias, o Comitê de Ministros poderá emitir resoluções provisórias, decisões ou recomendações, e continua supervisionando a execução.

Os procedimentos padrão e intensificado seguem traços distintos. O procedimento intensificado é dedicado a casos mais complexos e, assim, recebe uma atenção mais especial do Comitê de Ministros e do Departamento de Execução de Sentenças. Nesses processos quase sempre os casos são levados para discussão coletiva nas reuniões periódicas do Comitê, não sem antes passar pelo crivo do Departamento de Execução, que, caso necessário, pode procurar as autoridades nacionais para obter informações sobre as dificuldades na implementação das medidas devidas.

No caso do procedimento padrão, o Departamento segue a ideia de que casos menos complexos sejam tratados pelas próprias autoridades nacionais sem a assistência do Departamento de Execução, e são acompanhados apenas de acordo com informações prestadas em um formulário padrão escrito. Um exemplo são casos onde a condenação do Estado exige apenas o pagamento de uma indenização, que é realizada pelo Poder Executivo sem maiores burocracias. Somente em casos de negação da execução ou problemas na interpretação das medidas de reparação é que o Departamento dialoga com as autoridades nacionais e as partes envolvidas.

Esse método de trabalho resulta na imposição de um diálogo institucionalizado e técnico em nome de um aumento de eficiência. Veja-se que somente alguns casos, ainda que sobre o procedimento intensificado, é que irão entrar na pauta de debates do Comitê de Ministros, sob sugestão dos Estados ou do Departamento de Execução. Nesse sentido, a prática tem demonstrado que somente casos de demora injustificada na execução de sentenças e diferenças de interpretação entre 
DE ALMEIDA LEITE, Rodrigo; BORGES GAMA NETO, Ricardo. O recurso por incumprimento perante o tribunal europeu de direitos humanos: um reforço jurídico ao mecanismo político de supervisão de sentenças. Revista Eletrônica Direito e Política, Programa de Pós-Graduação Stricto Sensu em Ciência Jurídica da UNIVALI, Itajaí, v.14, n.1, $1^{0}$ quadrimestre de 2019. Disponível em: www.univali.br/direitoepolitica - ISSN 1980-7791

o Departamento de Execução e o Estado condenado sobre as medidas a serem executadas servem de critérios de eleição para entrar na pauta das reuniões do Comitê de Ministros ${ }^{38}$.

\section{O RECURSO POR INCUMPRIMENTO INSTITUÍDO PELO PROTOCOLO No}

\section{4}

Com a entrada em vigor do Protocolo no 14 , em 2010 39 , que alterou a CEDH, as funções do Comitê de Ministros foram melhoradas, e agora o TEDH também passa a fazer parte do processo de supervisão de sentenças.

Por meio desse protocolo, foram adicionados os parágrafos $3^{\circ}, 4^{\circ}$ e $5^{\circ}$ ao art. 46 da CEDH. O terceiro permite que quando o Comitê de Ministros considere que a supervisão da execução de uma sentença definitiva resulta obstaculizada por um problema de interpretação, o Comitê de Ministros possa enviar o caso para o Tribunal, para que este se pronuncie sobre a questão em dúvida. A decisão de reenvio ao Tribunal será tomada por maioria de dois terços dos votos dos representantes do Comitê.

Os parágrafos $4^{\circ}$ e $5^{\circ}$, por sua vez, regulamentam o que a doutrina denomina de recurso por incumprimento ${ }^{40}$. Esse procedimento pode ser exercido pelo Comitê de Ministros quando um Estado se nega a executar uma sentença. Nesse caso, o Comitê, após esgotamento das vias de diálogo para que se cumpra a decisão do

\footnotetext{
38 ABDELGAWAD, Elisabeth Lambert. Dialogue and the implementation of the European Court of Human Rights' Judgments, p. 350.

39 O Protocolo n. 14 entrou em vigor em 1 de junho de 2010.

40 Denominação adotada por GÓMEZ, Carmem Morte. Eficacia de las Sentencias del Tribunal Europeo de Derechos Humanos. In: Universidade del País Vasco (ed.). La Eficacia del Derecho Internacional de los Derechos Humanos. Cursos de Derechos Humanos de Donostia-San Sebastián. Bilbao: Universidad del País Vasco, Vol. XI, 2011, p. 225-242; ABDELGAWAD, Elisabeth Lambert. Le Protocole 14 et l'exécution des arrest de la Cour Européenne des Droits de L'Homme. In: COHEN-JONATHAN, Gerard; FLAUSS, Jean-françois (eds.). La reforme du système de controle contentieux de la Convention Européenne des Droits de L' homme. Bruxelles: Bruylant, 2005, p. 78-113; RIDRUEJO, José Antonio Pastor. El Protocolo número 14 a la Convención Europea de Derechos Humanos: ¿Estamos ante la reforma que necesita el Tribunali. Revista Española de Derecho Internacional, 2004, vol. LVI, n. 1, p. 141-149; e SUDRE, Fréderic. Droit européen et international des droits de l'homme, 9a. ed. Paris: Presses Universitaries de France, 2008.
} 
DE ALMEIDA LEITE, Rodrigo; BORGES GAMA NETO, Ricardo. O recurso por incumprimento perante o tribunal europeu de direitos humanos: um reforço jurídico ao mecanismo político de supervisão de sentenças. Revista Eletrônica Direito e Política, Programa de Pós-Graduação Stricto Sensu em Ciência Jurídica da UNIVALI, Itajaí, v.14, n.1, $1^{0}$ quadrimestre de 2019. Disponível em: www.univali.br/direitoepolitica - ISSN 1980-7791

TEDH, pode, por maioria de dois terços de seus membros, remeter o caso para o Tribunal, para que este se pronuncie sobre o descumprimento. Deste procedimento podem surgir duas decisões: (a) a primeira, na qual o Tribunal considera que houve uma violação no dever de cumprir a decisão e remete o caso ao Comitê de Ministros para que este examine as medidas a serem adotadas contra o Estado; e (b) o Tribunal determina que não houve incumprimento, e reenvia o processo para o Comitê, que assim o arquivará.

A valoração global da criação desse recurso por incumprimento tem sido positiva, pois permite ao TEDH participar do tema da execução de suas sentenças ${ }^{41}$. No entanto, apesar do pronunciamento do Tribunal, este continua sem poderes para sancionar os países que insistem em não cumprir as sentenças ${ }^{42}$.

Em relação aos aspectos técnicos desse recurso, o Comitê de Ministros será o único sujeito ativo desse procedimento, e, para que o processo seja analisado, deverá ser motivado e estar documentado com a sentença em questão, informações sobre o descumprimento, cópia da notificação do Comitê de Ministros ao Estado, entre outros. Ainda de acordo com o Regulamento do TEDH, o órgão responsável pela análise deste recurso é a Grande Sala ${ }^{43}$, e seu Presidente deverá notificar as partes para que apresentem suas razões, podendo ainda solicitar a realização de uma audiência ${ }^{44}$.

Ainda que não haja menção expressa no art. 46, caso o TEDH decida que houve uma violação do parágrafo $1^{0}$ do art. 46 da CEDH, ou seja, que ocorreu o descumprimento de uma sentença (obrigação de respeitar as sentenças do

\footnotetext{
41 RIDRUEJO, José Antonio Pastor. El Protocolo número 14 a la Convención Europea de Derechos Humanos: ¿Estamos ante la reforma que necesita el Tribunali.

42 SUDRE, Fréderic. Droit européen et international des droits de I'homme, p. 737.

${ }^{43}$ A Grande Sala também é chamada de Grande Câmara. Um caso ao chegar no TEDH pode ser julgado pelas seguintes estruturas: (a) um juiz singular; (b) um Comitê de 3 juízes; (c) uma Câmara de 7 juízes; e (d) pela Grande Câmara, composta de 17 juízes. Para uma melhor compreensão do tema, vide um organograma simplificado da estrutura do TEDH em: <http://echr.coe.int/Documents/Case_processing_Court_POR.pdf>. Acesso em 18 nov. 2018.

${ }^{44}$ Vid. arts. 94-99, do Regulamento do Tribunal Europeu dos Direitos Humanos, que entrou em vigor em 14 de novembro de 2016.2 Disponível em: <http://www.echr.coe.int/Documents/Rules_Court_ENG.pdf>. Acesso em: 18 nov. 2018.
} 
DE ALMEIDA LEITE, Rodrigo; BORGES GAMA NETO, Ricardo. O recurso por incumprimento perante o tribunal europeu de direitos humanos: um reforço jurídico ao mecanismo político de supervisão de sentenças. Revista Eletrônica Direito e Política, Programa de Pós-Graduação Stricto Sensu em Ciência Jurídica da UNIVALI, Itajaí, v.14, n.1, $1^{0}$ quadrimestre de 2019. Disponível em: www.univali.br/direitoepolitica - ISSN 1980-7791

Tribunal), esta decisão poderá permitir que o Comitê de Ministros utilize a via do art. $8^{\circ}$ do Estatuto do Conselho da Europa, que permite proceder com a suspensão do Estado e, inclusive, propor a sua expulsão da organização45.

Contudo, por mais que a inovação do Protocolo no 14 seja válida em seu objetivo de aprimorar a supervisão das sentenças, o mecanismo não é isento de críticas.

Abdelgawad ${ }^{46}$, ao analisar o recurso por incumprimento, demonstra preocupação com a possibilidade de utilização do mecanismo. Sua primeira crítica é direcionada com a restrição para a legitimidade ativa desse procedimento.

Na visão da autora, o monopólio do recurso nas mãos de um único órgão político (Comitê de Ministros) poderá explicar em parte a não utilização desse procedimento, limitando ou paralisando suas potencialidades. Complementa afirmando que é ainda mais difícil compreender a impossibilidade da Assembleia Parlamentária de figurar como ente legitimado para o recurso, pois também possui suas atividades na supervisão do cumprimento das sentenças do TEDH reconhecidas pelo Comitê. Caso o principal argumento para o monopólio seja não tumultuar o Tribunal com muitos recursos desse tipo (caso houvesse a possibilidade de que qualquer das partes e entes pudessem recorrer), era suficiente prever que o recurso seria destinado a uma das câmaras do TEDH, e não à Grande Sala (órgão principal) ${ }^{47}$.

Por outro lado, não se poderá alegar que esse recurso é complexo. Essa modalidade de procedimento não é um exercício novo para o Comitê de Ministros,

\footnotetext{
45 SANCHO, Ángel G. Chueca. El Nuevo Tribunal Europeo de Derechos Humanos (la entrada en vigor del Protocolo Adicional n. 14 en junio de 2010). Revista de Derecho Migratorio y Extranjería. n. 24, 2010, p. 225-226.

46 ABDELGAWAD, Elisabeth Lambert. L'exécution des jugements: les requêtes en manquement et en interprétation. In: BESSON, Samantha (ed.). La Cour européene des droits de I'homme après le Protocole 14. Premier bilan et perpectives. Genève: Schultess, 2011, p. 93-113.

47 ABDELGAWAD, Elisabeth Lambert. L'exécution des jugements: les requêtes en manquement et en interprétation, p. 95-99.
} 
DE ALMEIDA LEITE, Rodrigo; BORGES GAMA NETO, Ricardo. O recurso por incumprimento perante o tribunal europeu de direitos humanos: um reforço jurídico ao mecanismo político de supervisão de sentenças. Revista Eletrônica Direito e Política, Programa de Pós-Graduação Stricto Sensu em Ciência Jurídica da UNIVALI, Itajaí, v.14, n.1, $1^{0}$ quadrimestre de 2019. Disponível em: www.univali.br/direitoepolitica - ISSN 1980-7791

que está acostumado a tomar decisões e redigir memorandos e outros documentos detalhando as medidas tomadas pelos Estados para a execução das sentenças ${ }^{48}$.

O que mais poderá fazer com que esse recurso seja limitado são as reticências políticas, pois sancionar um Estado pela violação de um tratado internacional de direitos humanos no seio do Conselho da Europa é algo muito sensível. E tal fato se deve porque provavelmente são os representantes mesmos dos Estados no Comitê de Ministros que devem tomar a decisão de acionar o procedimento, conscientes de que nenhum país está imune a esse recurso ${ }^{49}$.

Deve-se ressaltar, também, que caso o TEDH aceite o recurso e determine que houve o descumprimento da sentença, a decisão terá efeitos unicamente declaratórios, deixando-se ao Comitê de Ministros a adoção da medida sancionatória mais correta a ser tomada em cada caso. Dessa forma, o procedimento está coberto de risco, pois: (a) o Comitê de Ministros poderá não tomar as medidas necessária por razões políticas; e (b) o TEDH poderá decidir o contrário ao requerido pelo Comitê, e o caso será arquivado50.

Caso esta última possibilidade ocorra, pode ser uma fonte de dificuldades, e assim teria sido preferível para o Comitê de Ministros que eles pudessem continuar o controle da supervisão do caso, pois não há garantias de que o TEDH seja sensível à complexidade do processo de supervisão realizado pelo Comitê, com todas as questões políticas que envolve ${ }^{51}$.

Essas questões refletem a particularidade que há nesse recurso, que não deve servir de instrumento nas mãos do Comitê de Ministros para criticar as sentenças do TEDH, mas sim para informar ao Tribunal das dificuldades na execução das

\footnotetext{
48 ABDELGAWAD, Elisabeth Lambert. L'exécution des jugements: les requêtes en manquement et en interprétation, p. 99.

${ }^{49}$ ABDELGAWAD, Elisabeth Lambert. L'exécution des jugements: les requêtes en manquement et en interprétation, p. 100.

${ }^{50}$ ABDELGAWAD, Elisabeth Lambert. L'exécution des jugements: les requêtes en manquement et en interprétation, p. 100.

${ }^{51}$ ABDELGAWAD, Elisabeth Lambert. L'exécution des jugements: les requêtes en manquement et en interprétation, p. 93.
} 
DE ALMEIDA LEITE, Rodrigo; BORGES GAMA NETO, Ricardo. O recurso por incumprimento perante o tribunal europeu de direitos humanos: um reforço jurídico ao mecanismo político de supervisão de sentenças. Revista Eletrônica Direito e Política, Programa de Pós-Graduação Stricto Sensu em Ciência Jurídica da UNIVALI, Itajaí, v.14, n.1, $1^{0}$ quadrimestre de 2019. Disponível em: www.univali.br/direitoepolitica - ISSN 1980-7791

sentenças. Neste ponto particular, Abdelgawad ${ }^{52}$ também critica o procedimento, pois, ao levar o caso ao TEDH, o Comitê de Ministros está assumindo que não logrou êxito na sua missão de supervisão do cumprimento das sentenças, o que poderá fazer com que ele seja relutante na hora de utilizar esse recurso.

Outra crítica quanto à efetividade do recurso por incumprimento pode ser encontrada em Jiméne ${ }^{53}$, que afirma que caso o TEDH decida que houve uma violação do art. 46.1 da CEDH em uma sentença, em virtude de um recurso por incumprimento, deverá enviar o caso para o Comitê de Ministros, e este poderá utilizar o art. $8^{\circ}$ do Estatuto do Conselho da Europa, opção que já foi declarada no Relatório Explicativo do Protocolo no 14 como "potencialmente contraproducente". Para a autora, em realidade, parece que toda a virtude desta medida "está en la repercusión pública que esta vuelta al TEDH pueda generar y en la presión que aquella pueda ejercer sobre el Estado infractor". Ou seja, volta-se a confiar no clássico estilo do direito internacional geral, que consiste na pressão da repercussão pública para que se motive um Estado a cumprir uma decisão internacional ${ }^{54}$.

O procedimento, como já foi mostrado, repercutiu na doutrina tanto positiva como negativamente. Neste último sentido, Alvarado também expressa que o recurso por incumprimento não adiciona qualquer tipo de consequência séria para os países declarados incumpridores, o que ao final somente vai trazer mais carga de trabalho para o $\mathrm{TEDH}^{55}$. Alcega também aponta que a alternativa mais dura do recurso - a ameaça de expulsão do Estado do Conselho da Europa, não aporta nada positivo, nem à possível execução da sentença tampouco à melhora do nível

52 ABDELGAWAD, Elisabeth Lambert. The Court as part of the Council of Europe: the Parliamentary Assembly and the Committee of Ministers, p. 280.

53 JIMÉNEZ, Argelia Queralt. La protección de derechos y libertades en Europa tras la entrada en vigor del Protocolo núm. 14 al CEDH. Revista Española de Derecho Europeo, n. 36, 2010, p. 487519.

54 JIMÉNEZ, Argelia Queralt. La protección de derechos y libertades en Europa tras la entrada en vigor del Protocolo núm. 14 al CEDH, p. 508-510. Este também é o posicionamento de GÓMEZ, Carmem Morte. Eficacia de las Sentencias del Tribunal Europeo de Derechos Humanos, p. 234.

55 ALVARADO, Paola Andrea Acosta. Tribunal Europeo y Corte Interamericana de Derechos Humanos: ¿escenarios idóneos para la garantía del derecho de acceso a la justicia constitucionali. Bogotá: Universidad Externado de Colombia, 2008, p. 105-106. 
DE ALMEIDA LEITE, Rodrigo; BORGES GAMA NETO, Ricardo. O recurso por incumprimento perante o tribunal europeu de direitos humanos: um reforço jurídico ao mecanismo político de supervisão de sentenças. Revista Eletrônica Direito e Política, Programa de Pós-Graduação Stricto Sensu em Ciência Jurídica da UNIVALI, Itajaí, v.14, n.1, $1^{0}$ quadrimestre de 2019. Disponível em: www.univali.br/direitoepolitica - ISSN 1980-7791

de proteção dos direitos humanos no país condenado, o qual, uma vez expulso, fica mais distante dos instrumentos de pressão que podem ser exercidos no seio da Organização ${ }^{56}$.

Todavia, o recurso é válido e pode colaborar no processo de supervisão de cumprimento das sentenças ${ }^{57}$. O TEDH logicamente pode ver-se com uma carga maior de trabalho, mas quando o Comitê de Ministros elabora seus relatórios, passa a estabelecer com mais detalhes as causas do descumprimento das sentenças e, assim, pode facilitar o trabalho do $\mathrm{TEDH}^{58}$. Ademais, com a sentença proveniente do recurso por incumprimento, o Comitê de Ministros agora tem não apenas razões políticas para sancionar um Estado, mas também conta com o "peso" de uma decisão judicial do tribunal internacional do sistema. Assim, evitam-se críticas acerca das implicações políticas de uma decisão do Comitê de Ministros ${ }^{59}$.

Por certo, o Sistema Europeu ainda não evoluiu, com o Protocolo no 14 e modificações posteriores, para a criação de um sistema de sanções fora do campo político, mas ainda assim o recurso por incumprimento pode ajudar a construir o sentimento de constrangimento que os Estados terão ao resistirem em cumprir as decisões do TEDH.

Deve-se ressaltar que as críticas e considerações sobre esse recurso são as primeiras impressões de uma via de criação recente. Na doutrina encontrada e no site do Comitê de Ministros e do TEDH não há informações sobre a existência da utilização do procedimento. Assim, somente a prática poderá demonstrar o seu

\footnotetext{
56 ALCEGA, Sergio Salinas. El nuevo procedimiento de control de la ejecucion de las sentencias del Tribunal Europeo de Derechos Humanos tras el proceso de Interlaken, p. 7.

57 CAFLISCH, Lucius. L'efficacité du systéme européen de protection des droits de I'homme. In: CAFLISCH, Lucius; GARCÍA, Romualdo Bermejo; DÍEZ-HOCHLEITNER, et al (Org.). El Derecho Internacional: Normas, Hechos y Valores. Liber Amicorum José Antonio Pastor Ridruejo. Madrid: Universidad Complutense de Madrid, 2005, p. 55-56.
}

58 ROCA, Javier García; ALCALÁ, Humberto Nogueira; GISBERT, Rafael Bustos. La comunicación entre ambos sistemas y las características del diálogo. In: El diálogo entre los Sistemas Europeo y Americano de Derechos Humanos. ROCA, Javier García; FERNÁNDEZ, Pablo Antonio; SANTOLAYA, Pablo (eds.). Madrid: Civitas, 2012, p. 73.

59 SALVIOLI, Fábian; ZANGHI, Claudio. El Tribunal Europeo de Derechos Humanos y la Corte Interamericana de Derechos Humanos. In: SALVIOLI, Fábian; ZANGHI, Claudio (eds). Jurisprudencia Regional Comparada de Derechos Humanos. El Tribunal Europeo y la Corte Interamericana. Valencia: Tirant lo Blach, 2013, p. 66. 
DE ALMEIDA LEITE, Rodrigo; BORGES GAMA NETO, Ricardo. O recurso por incumprimento perante o tribunal europeu de direitos humanos: um reforço jurídico ao mecanismo político de supervisão de sentenças. Revista Eletrônica Direito e Política, Programa de Pós-Graduação Stricto Sensu em Ciência Jurídica da UNIVALI, Itajaí, v.14, n.1, $1^{0}$ quadrimestre de 2019. Disponível em: www.univali.br/direitoepolitica - ISSN 1980-7791

êxito ou fracasso. No entanto, ante a modificação no procedimento de supervisão efetuada desde 2010 com a Conferência de Interlaken, que revestiu a supervisão de um caráter mais cooperativo e menos sancionatório, vislumbra-se que dificilmente esse recurso será utilizado com frequência.

\section{CONSIDERAÇÕES FINAIS}

Muito embora o recurso por incumprimento seja uma ferramenta a mais na luta pelo respeito às sentenças do $\mathrm{TEDH}$, o instrumento nunca foi utilizado. A doutrina já apontou os pontos positivos e negativos do recurso, havendo posicionamentos a favor e contra. Londras e Dzehtsiarou ${ }^{60}$ inclusive chegam a denominar o recurso de uma solução inadequada por razões de praticidade, futilidade e de potencial backlash do sistema. Na visão dos autores, a não execução de uma sentença é um problema complexo e policêntrico, de cunho político, capaz de resistir a soluções "simples".

O instrumento traz um quórum de dois terços dos representantes do Comitê de Ministros para ser aprovado, que obtém dificuldades para se alcançar, pois a gravidade da não execução da sentença deve chegar ao limite da exaustão dialógica política. Por outro lado, para que o Comitê cogite a sua utilização, estará implicitamente aceitando que a política falhou, e instituições internacionais não costumam manifestar suas falhas prontamente. Por sua vez, o potencial backlash do sistema estaria no fato de que em alguns Estados membros existe um profundo e popular ceticismo quanto ao papel do TEDH, e envolver esta Corte no último procedimento de execução, exercendo um papel político, poderia colocar combustível no fogo do discurso da ilegitimidade do tribunal ${ }^{61}$.

\footnotetext{
60 LONDRAS, Fiona De; DZEHTSIAROU, Kanstantsin. Mission Impossible? Addressing Non-Execution Through Infringement Proceedings In The European Court Of Human Rights. International and Comparative Law Quarterly, vol 66, April 2017 p. 468.

61 LONDRAS, Fiona De; DZEHTSIAROU, Kanstantsin. Mission Impossible? Addressing Non-Execution Through Infringement Proceedings In The European Court Of Human Rights, p. 483-486.
} 
DE ALMEIDA LEITE, Rodrigo; BORGES GAMA NETO, Ricardo. O recurso por incumprimento perante o tribunal europeu de direitos humanos: um reforço jurídico ao mecanismo político de supervisão de sentenças. Revista Eletrônica Direito e Política, Programa de Pós-Graduação Stricto Sensu em Ciência Jurídica da UNIVALI, Itajaí, v.14, n.1, $1^{0}$ quadrimestre de 2019. Disponível em: www.univali.br/direitoepolitica - ISSN 1980-7791

Nos termos como regulamentado, o recurso por incumprimento é percebido mais como uma punição pela não execução de sentença do que uma ferramenta discursiva criada para encontrar uma solução para o problema. Essa punição seria ainda "sem dentes" (toothless), posto que o TEDH não tem competência para impor qualquer sanção pelo descumprimento de seu julgamento ${ }^{62}$.

Embora exista essa visão negativa, não se pode negar que o Sistema Europeu de Direitos Humanos evoluiu enormemente, estabelecendo procedimentos claros de supervisão, em um ambiente em que cada sentença que não é cumprida prontamente passa por um processo de supervisão política.

Neste sentido, Keller e Marti ${ }^{63}$ apontam que esse novo recurso por incumprimento até agora tem apenas natureza simbólica e permaneceu letra morta. No entanto, uma constatação judicial sobre o descumprimento de uma sentença pode exercer pressão adicional sobre o Estado em questão para garantir a execução do julgamento. Dessa forma, o sistema de supervisão política, que tem se notabilizado útil para facilitar o cumprimento por meio do diálogo diplomático e pressão dos pares, seria complementado por um procedimento de responsabilidade jurídica, que interviria se a primeira opção falhasse.

\section{REFERÊNCIAS DAS FONTES CITADAS}

ABDELGAWAD, Elisabeth Lambert. L'exécution des jugements: les requêtes en manquement et en interprétation. In: BESSON, Samantha (ed.). La Cour européene des droits de I' homme après le Protocole 14. Premier bilan et perpectives., Genève: Schultess, 2011, p. 93-113.

. Le Protocole 14 et I'exécution des arrest de la Cour Européenne des Droits de L'Homme. In: COHEN-JONATHAN, Gerard; FLAUSS, Jean-françois (eds.). La reforme du système de controle contentieux de la Convention

\footnotetext{
62 LONDRAS, Fiona De; DZEHTSIAROU, Kanstantsin. Mission Impossible? Addressing Non-Execution Through Infringement Proceedings In The European Court Of Human Rights, p. 485.

63 KELLER, Helen; MARTI, Cedric. Reconceptualizing Implementation: The Judicialization of the Execution of the European Court of Human Rights' Judgments. The European Journal of International Law, vol. 26, n. 4, p. 849-850.
} 
DE ALMEIDA LEITE, Rodrigo; BORGES GAMA NETO, Ricardo. O recurso por incumprimento perante o tribunal europeu de direitos humanos: um reforço jurídico ao mecanismo político de supervisão de sentenças. Revista Eletrônica Direito e Política, Programa de Pós-Graduação Stricto Sensu em Ciência Jurídica da UNIVALI, Itajaí, v.14, n.1, $1^{0}$ quadrimestre de 2019. Disponível em: www.univali.br/direitoepolitica - ISSN 1980-7791

Européenne des Droits de L’homme. Bruxelles: Bruylant, 2005, p. 78-113.

. Dialogue and the implementation of the European Court of Human Rights' Judgments. Netherlands Quarterly of Human Rights, vol. 34/4, 2016, p. 340-363.

The Court as part of the Council of Europe: the Parliamentary Assembly and the Committee of Ministers. In: FOLLESDAL, Andreas; PETERS, Birgit; ULFSTEIN, Geir (eds). Constituting Europe. The European Court of Human Rights in a National, European and Global Context. Cambridge, Cambridge University Press, 2013, p. 263-300.

ALCEGA, Sergio Salinas. El nuevo procedimiento de control de la ejecucion de las sentencias del Tribunal Europeo de Derechos Humanos tras el proceso de Interlaken. La evolución técnica de un mecanismo político. Revista General de Derecho Europeo, n. 36, 2015, p. 1-25.

ALVARADO, Paola Andrea Acosta. Tribunal Europeo y Corte Interamericana de Derechos Humanos: ¿escenarios idóneos para la garantía del derecho de acceso a la justicia constitucionali. Bogotá: Universidad Externado de Colombia, 2008.

ANAGNOSTOU, Dia; MUNGIU-PIPPIDI, Alina. Domestic Implementation of Human Rights Judgments in Europe: Legal Infrastructure and Government Effectiveness Matter. The European Journal of International Law, vol. 25, n. 1, 2014, p. 205-227.

BASCH, Fernando; FILIPPINI, Leonard; LAYA, Ana; NINO, Mariano; et al. The Effectiveness of the Inter-American System of Human Rights Protection: A Quantitative Approach to its Functioning and Compliance with its Decisions. SUR - International Journal on Human Rights, vol. 7, n. 12, 2010, p. 9-36.

BATES, Ed. The Evolution of the European Convention on Human Rights: From Its Inception to the Creation of a Permanent Court of Human Rights. New York: Oxford University Press, 2011.

BRICEÑO-DONN, Marcela. El papel de los actores del Sistema Interamericano en el Proceso de Fortalecimiento. Revista IIDH, n. 30-31, 2001, p. 237-243.

CAFLISCH, Lucius. L'efficacité du systéme européen de protection des droits de I'homme. In: CAFLISCH, Lucius; GARCÍA, Romualdo Bermejo; DÍEZHOCHLEITNER, et al (Org.). El Derecho Internacional: Normas, Hechos y Valores. Liber Amicorum José Antonio Pastor Ridruejo. Madrid: Universidad Complutense de Madrid, 2005, p. 43-58.

ÇALI, Basaki; KOCH, Anne. Foxes Guarding the Foxes? The Peer Review of Human Rights Judgments by the Committee of Ministers of the Council of Europe. Human Righs Law Review, vol. 14, 2014, p. 301-325. 
DE ALMEIDA LEITE, Rodrigo; BORGES GAMA NETO, Ricardo. O recurso por incumprimento perante o tribunal europeu de direitos humanos: um reforço jurídico ao mecanismo político de supervisão de sentenças. Revista Eletrônica Direito e Política, Programa de Pós-Graduação Stricto Sensu em Ciência Jurídica da UNIVALI, Itajaí, v.14, n.1, $1^{0}$ quadrimestre de 2019. Disponível em: www.univali.br/direitoepolitica - ISSN 1980-7791

CAVALLARO, James L; BREWER, Stephanie. Reevaluating Regional Human Rights Litigation in the Twenty-First Century: The Case of the Inter-American Court. The American Journal of International Law, vol. 102, 2008, p. 768-827.

CHRISTOFFERSEN, Jonas; MADSEN, Mikael Rask. Introduction. In: CHRISTOFFERSEN, Jonas; MADSEN, Mikael Rask (eds.). The European Court of Human Rights between Law and Politics. New York: Oxford University Press, 2011, p. 1-16.

CONSELHO DA EUROPA. Rules of the Committee of Ministers for the supervision of the execution of judgments and of the terms of friendly settlements. Adopted by the Committee of Ministers on 10 May 2006 at the 964th meeting of the Ministers' Deputies and amended on 18 January 2017 at the 1275 th meeting of the Ministers' Deputies. Estrasburgo, França, 10 maio 2006. Disponível em: <https://rm.coe.int/16806eebf0>. Acesso em: 9 nov. 2018.

Convenção Europeia dos Direitos do Homem. Roma, 4 nov. 1950. Disponível em: <https://www.echr. coe.int/Documents/Convention_POR.pdf>. Acesso em: 9 nov. 2018.

GARCÉS, Andrée Viana. Sistemas Europeo y Americano de Protección de Derechos Humanos. Coincidencias, Fraccionamientos Temporales y Mutuas Influencias. In: SÁNCHEZ, Miguel Revenga; GARCÉS, Andrée Viana (eds.): Tendencias Jurisprudenciales de La Corte Interamericana y el Tribunal Europeo de Derechos Humanos. Valencia: Tirant lo Blanch, 2008, p. 17-70.

GÓMEZ, Carmem Morte. Eficacia de las Sentencias del Tribunal Europeo de Derechos Humanos. In: Universidade del País Vasco (ed.). La Eficacia del Derecho Internacional de los Derechos Humanos. Cursos de Derechos Humanos de Donostia-San Sebastián. Bilbao: Universidad del País Vasco, Vol. XI, 2011, p. 225-242.

GONZÁLEZ-SALZBERG, Damián A. The Effectiveness Of The Inter-American Human Rights System: A Study Of The American States' Compliance With The Judgments Of The Inter-American Court Of Human Rights. International Law: Revista Colombiana de Derecho Internanacional, n. 15, 2010, p. 115-142.

GREWAL, Sharanbir; VOETEN, Erik. The Politics of Implementing European Court of Human Rights Judgements, 2012, Paper disponível em SSRN: <https://ssrn.com/abstract=1988258>. Acesso em: 9 nov. 2018.

HAWKINS, Darren; JACOBY, Wade. Partial compliance: a comparison of the European and inter-American courts of human rights. Journal of International Law and International Relations, vol. 6, n. 1, 2010, p. 35-85.

HILLEBRECHT, Courtney. Domestic Politics and International Human Rights Tribunals. The Problem of Compliance. New York: Cambridge University Press, 2014. 
DE ALMEIDA LEITE, Rodrigo; BORGES GAMA NETO, Ricardo. O recurso por incumprimento perante o tribunal europeu de direitos humanos: um reforço jurídico ao mecanismo político de supervisão de sentenças. Revista Eletrônica Direito e Política, Programa de Pós-Graduação Stricto Sensu em Ciência Jurídica da UNIVALI, Itajaí, v.14, n.1, $1^{0}$ quadrimestre de 2019. Disponível em: www.univali.br/direitoepolitica - ISSN 1980-7791

HUNEEUS, Alexandra. Courts Resisting Courts: Lessons from the Inter-American Court's Struggle to Enforce Human Rights. Cornell International Law Journal, vol. 44, 2011, p. 493-533.

JIMÉNEZ, Argelia Queralt. La protección de derechos y libertades en Europa tras la entrada en vigor del Protocolo núm. 14 al CEDH. Revista Española de Derecho Europeo, n. 36, 2010, p. 487-519.

KELLER, Helen; MARTI, Cedric. Reconceptualizing Implementation: The Judicialization of the Execution of the European Court of Human Rights' Judgments. The European Journal of International Law, vol. 26, n. 4, p. 829-850.

KRSTICEVIC, V.: Reflexiones sobre la ejecución de sentencias de las decisiones del sistema interamericano de protección de derechos humanos. In: KRSTICEVIC, V.; TOJO, L. (coord.): Implementación de las decisiones del Sistema Interamericano de Derechos Humanos: Jurisprudencia, normativa y experiencias nacionales. Buenos Aires: Center for Justice and International Law CEJIL, 2007, p. 15-112.

LEACH, Philip. Taking a Case to the European Court of Human Rights. 3. ed. New York: Oxford University Press, 2011.

LEITE, Rodrigo. Análise Dos Processos E Atores Políticos Na Supervisão De Sentenças Da Corte Interamericana De Direitos Humanos. In: Simone P. Viscarra; Michele G. Massuchin; Sandra Avi dos Santos; Lucas R. Mesquita; Lorena Granja Hernández; Helga N. Almeida. (Org.). América Latina em foco: Novas perspectivas de análise sobre a região. 1ed. Porto Alegre: Terra da Ideia, 2017, p. 99-119.

LONDRAS, Fiona De; DZEHTSIAROU, Kanstantsin. Mission Impossible? Addressing Non-Execution Through Infringement Proceedings In The European Court Of Human Rights. International and Comparative Law Quarterly, vol 66, April 2017 p. 467-490.

MANTOUVALOU, Virginia; VOYATZIS, Panayotis. The Council of Europe and the protection of human rights. In: JOSEPH, Sarah; MCBETH, Adam. Research handbook on international human rights Law. Reino Unido: Edward Elgar, 2010.

ODRÍA, Alberto Borea. Propuesta de modificación a la legislación del sistema interamericano de protección de los derechos humanos. In: Corte Interamericana de Derechos Humanos (org.). El Sistema Interamericano de Protección de los Derechos Humanos en el Umbral del Siglo XXI, 2a. ed., Corte Interamericana de Derechos Humanos, San José, 2003, p. 533-546.

PIRES, Maria José Morais. Execução dos Acórdãos do Tribunal Europeo dos Direitos do Homem - O Protocolo n. 14 à Convenção Europeia dos Direitos do Homem. In: MIRANDA, Jorge (coord). Homenagem ao Prof. Doctor André Gonçalves Pereira. Lisboa: Ed. Coimbra, 2006, p. 821-841. 
DE ALMEIDA LEITE, Rodrigo; BORGES GAMA NETO, Ricardo. O recurso por incumprimento perante o tribunal europeu de direitos humanos: um reforço jurídico ao mecanismo político de supervisão de sentenças. Revista Eletrônica Direito e Política, Programa de Pós-Graduação Stricto Sensu em Ciência Jurídica da UNIVALI, Itajaí, v.14, n.1, $1^{0}$ quadrimestre de 2019. Disponível em: www.univali.br/direitoepolitica - ISSN 1980-7791

RIDRUEJO, José Antonio Pastor. El Protocolo número 14 a la Convención Europea de Derechos Humanos: ¿Estamos ante la reforma que necesita el Tribunali. Revista Española de Derecho Internacional, 2004, vol. LVI, n. 1, p. 141-149.

ROCA, Javier García; ALCALÁ, Humberto Nogueira; GISBERT, Rafael Bustos. La comunicación entre ambos sistemas y las características del diálogo. In: EI diálogo entre los Sistemas Europeo y Americano de Derechos Humanos. ROCA, Javier García; FERNÁNDEZ, Pablo Antonio; SANTOLAYA, Pablo (eds.). Madrid: Civitas, 2012, p. 66-107.

RODRÍGUEZ-PINZÓN, Diego; MARTIN, Claudia. The Inter-American human rights system: selected examples of its supervisory work. In: JOSEPH, Sarah.; MCBETH, Adam. (eds.). Research Handbook on International Human Rights Law. Northampton: Edward Elgar Publishing Limited, 2010, p. 353-387.

SALVIOLI, Fábian; ZANGHI, Claudio. El Tribunal Europeo de Derechos Humanos y la Corte Interamericana de Derechos Humanos. In: SALVIOLI, Fábian; ZANGHI, Claudio (eds). Jurisprudencia Regional Comparada de Derechos Humanos. El Tribunal Europeo y la Corte Interamericana. Valencia: Tirant lo Blach, 2013, p. 17-66.

SANCHO, Ángel G. Chueca. El Nuevo Tribunal Europeo de Derechos Humanos (la entrada en vigor del Protocolo Adicional n. 14 en junio de 2010). Revista de Derecho Migratorio y Extranjería. n. 24, 2010, p. 217-230.

SCHNEIDER, Jan. Implementation of Judgments: Should Supervision Be Unlinked From The General Assembly Of The Organization Of American States? Revista Interamericana y Europea de Derechos Humanos - Inter-American and European Human Rights Journal ,v. 5, n.1, 2012, p. 197-215.

SUDRE, Fréderic. Droit européen et international des droits de I'homme, 9a. ed. Paris: Presses Universitaries de France, 2008.

SUNDBERG, Fredrik G. E. Control of Execution of Decisions Under the ECHR Some Remarks on the Committee of Ministers' Control of the Proper Implementation of Decisions Finding Violations of The Convention. In: ALFREDSSON, Gudmundur; GRIMHEDEN, Jonas; RAMCHARAN, Bertram G. et al (eds.). International Human Rights. Monitoring Mechanisms. Essay in Honour of Jakob Th. Moller. Haya: Martinus Nijhoff Publishers, 2001, p. 561-586.

VOETEN, Erik. Does a Professional Judiciary Induce More Compliance?: Evidence from the European Court of Human Rights. Paper prepared for presentation at the ISA Convention, San Diego April, 2012, p. 1-39. Disponível em: <https://www.jus.uio.no/pluricourts/english/projects/multirights/docs/voetenlegal-justifications.pdf $>$. Acesso em: 10 nov. 2018. 
DE ALMEIDA LEITE, Rodrigo; BORGES GAMA NETO, Ricardo. O recurso por incumprimento perante o tribunal europeu de direitos humanos: um reforço jurídico ao mecanismo político de supervisão de sentenças. Revista Eletrônica Direito e Política, Programa de Pós-Graduação Stricto Sensu em Ciência Jurídica da UNIVALI, Itajaí, v.14, n.1, $1^{0}$ quadrimestre de 2019. Disponível em: www.univali.br/direitoepolitica - ISSN 1980-7791

ZAVERUCHA, Jorge; LEITE, Rodrigo de Almeida. A impunidade de agentes estatais nos casos julgados pela Corte Interamericana. Revista Brasileira de Segurança Pública, vol. 10, n. 1, 2016, p. 88-107.

RECIBIDO EM: 12/03/2019

APROVADO EM: 02/04/2019 